\title{
Repositorios institucionales y redes sociales académicas: el acceso abierto a las publicaciones científicas como objetivo y como negocio
}

Tony Hernández-Pérez | Dpto. de Biblioteconomía y Documentación, Universidad Carlos III de Madrid

URL de la contribución <www.iaph.es/revistaph/index.php/revistaph/article/view/4678>

Siempre conviene recordar la historia y retomar las esencias. La Budapest Open Access Initiative (BOAI), la primera declaración sobre acceso abierto a las publicaciones científicas, cumplirá 18 años el próximo 14 de mayo de 2020. Con motivo de su décimo aniversario, la BOAl redactó en 2012 unas recomendaciones para los próximos 10 años que se resumen en cuatro apartados: políticas de acceso abierto; licencias y reutilización; infraestructura y sostenibilidad; y promoción y coordinación (MELERO; BABINI, 2012).

Desde el principio, la BOAl otorgaba a los repositorios institucionales, también a los temáticos, un rol preponderante en el desarrollo del acceso abierto y en su revisión de los diez años se mostraba claramente a favor de "ayudar a los autores a pagar cuotas razonables para la publicación en revistas de acceso abierto de pago por publicar, y encontrar formas similares para apoyar o subsidiar las revistas de acceso abierto que no cobren por publicar". Los repositorios, institucionales y temáticos, son las infraestructuras que menciona la BOAI, obviando en su declaración, ni los repositorios o plataformas de las editoriales científicas, ni mucho menos las redes sociales académicas como Researchgate.net o Academia.edu.

En un excelente artículo, Ángel Borrego (BORREGO, 2017) analizó 1.031 artículos de autores españoles publicados en 760 revistas en 2014 para comparar cuántos de ellos se encontraban en repositorios institucionales y cuántos en ResearchGate. ¿Adivinan el resultado? En repositorios institucionales estaban disponibles 114 artículos $(11,1 \%)$ mientras que en ResearchGate se pudieron encontrar metadatos de 984 artículos $(95,4 \%$ de la

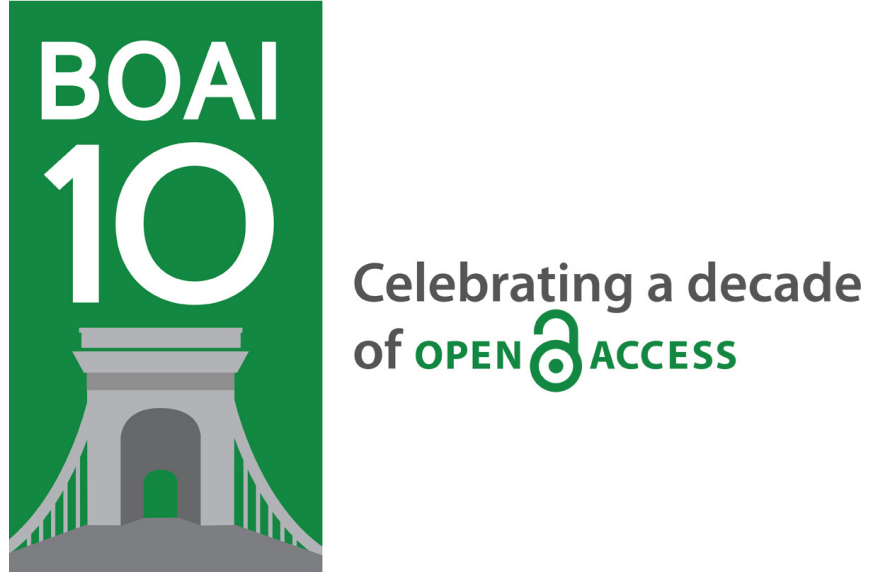

muestra) y 565 artículos (el 54,8 \% de la muestra) a texto completo. El texto de Borrego ofrece muchos más detalles, cuántos se publicaron en revistas OA, cuántos en revistas de pago, las políticas de los editores respecto al depósito de los artículos en repositorios, etc. Repositorios institucionales (11,1\%) ResearchGate $(54,8 \%)$. Al margen de las posibles críticas a ResearchGate por algunas malas prácticas, ¿no significa esto un fracaso sin paliativos de los repositorios institucionales frente a ResearchGate? Ya les adelanto mi respuesta: no.

\section{Algunos errores de los repositorios institucionales}

No, porque la mayor parte de las bibliotecas de investigación, encargadas generalmente de gestionar los repositorios institucionales, no compiten con ResearchGate. En general pertenecen a instituciones públicas y sus fines, el bien común en forma de patrimonio o de mejora de la sociedad a través de la ciencia, difieren sustancialmente de empresas privadas como ResearchGate o 
a debate Repositorios y redes sociales académicas para la transferencia del conocimiento abierto

| coordina Remedios Melero Melero

Academia, cuyo fin fundamental es el lucro de sus propietarios. No hay mucho que objetar, empresas privadas se benefician de datos abiertos que genera la administración pública para mejorar apps de pago o que obtienen beneficio a través de la publicidad, para mejorar nuestra experiencia sobre el transporte público o información meteorológica para agricultores.

Lo que sí debemos analizar y lo que debería ser obligatorio revisar son las razones por las que las bibliotecas de investigación tienen un rendimiento tan bajo en comparación con este tipo de empresas. Sin duda, sería necesario realizar un estudio serio, pero aquí van algunas hipótesis que habría que contrastar.

> Deficiente política de información sobre los repositorios: errores en los inicios de los repositorios institucionales, cuando además de los artículos de investigación (revisados por pares, como subraya la BOAI) los profesores encontraban en los repositorios apuntes de un profesor o trabajos de estudiantes. Es cierto que se ha ido corrigiendo, pero... aún cuesta muchísimo encontrar en muchos repositorios cuál es la política de depósito. Y aún queda el poso entre muchos investigadores, convenientemente estimulado por los intereses de las grandes editoriales, de la escasa calidad de lo que se puede encontrar en esos repositorios. Muy injusto, sí, pero real.

> Fallidas campañas de promoción, de concienciación sobre el acceso abierto. Sigue siendo sorprendente la confusión y falta de conocimiento entre los investigadores respecto al acceso abierto. $Y$ si sorprende entre los investigadores en general, no digamos de la falta de conciencia entre las autoridades universitarias, algo que poco a poco se ha ido corrigiendo. Las bibliotecas se encargaron, y bien, de las infraestructuras, pero no encontraron apoyo ni en las autoridades universitarias para dotar de contenidos e importancia a los repositorios ni en los investigadores, que siguen creyendo a pies juntillas que lo único que vale es publicar en revistas con factor de impacto y que todo lo demás resulta secundario porque las autoridades, ni las de los centros de inves- tigación, ni las agencias financiadoras hasta hace bien poco, lo valoraban. No se puede culpar a las bibliotecas, pero... seguramente se pudo, se puede hacer más.

$>$ Escasa eficiencia en el desarrollo de los repositorios. Procedimientos largos, con comprobaciones sobre derechos o versiones que muchas veces exigen un esfuerzo suplementario de los investigadores para ver su artículo ya aceptado o publicado en una revista en el repositorio institucional. Las bibliotecas de investigación, después de hacer un esfuerzo porque los investigadores de sus instituciones tengan su identificador ORCID, siguen sin utilizar a gran escala herramientas para localizar al menos metadatos de los artículos de sus investigadores en las bases de datos comerciales, a las que no exigen servicios para que les ofrezcan los metadatos de todo lo que lleve alguna señal de pertenecer a su institución. Igual que no se entiende por qué no rastrean, como sí hace ResearchGate, bases de datos comerciales o repositorios como PubMed, la NASA, arXiv o cualquier otro repositorio que pueda servir como fuente para el propio repositorio institucional. Seguramente la ratio de depósito de publicaciones en los repositorios institucionales esté por encima del 11,1\% que reflejaba el artículo de Borrego, pero seguramente sí está aún muy por detrás del 54,8\% que recogía ResearchGate en el mismo estudio.

Conste que no se pretende identificar "culpables". Los profesionales de las bibliotecas hacen su trabajo lo mejor que saben y pueden, en función de sus recursos. Cada investigador es responsable de su ética y de su comportamiento. Promover o no los resultados de la investigación de cada cual para que sean conocidos por la sociedad por razones de estímulo económico, por ser una obligación que marcan las autoridades o por querer contribuir a la ciencia, a las ciencias sociales o al conocimiento humanístico, no puede consistir en delegar la tarea en otros (bibliotecarios, autoridades universitarias o agencias de investigación) sino en cumplir con el compromiso moral de cada cual con la sociedad que le confía esa función investigadora y por la que, además, le retribuye. 


\section{Una nueva oportunidad para las bibliotecas de investigación en la ciencia abierta}

El movimiento de acceso abierto probablemente esté llegando a un punto de inflexión (ASPESI; BRAND, 2020). La presión de las agencias financiadoras, el Plan S, prácticas piratas como Sci-Hub o los acuerdos transformadores, están forzando a las grandes editoriales a moverse hacia nuevos modelos de negocio para seguir obteniendo beneficios en donde el pago por suscripción empieza a dejar paso al pago por publicar. No veremos el acceso abierto a las publicaciones al $100 \%$ de forma inmediata, pero... nos iremos acercando.

Las empresas de las grandes editoriales de revistas científicas se van moviendo poco a poco hacia el negocio de los datos. Ahora que los datos de investigación empiezan a considerarse un valor, ¿qué instituciones de investigación tienen capacidad para almacenar y gestionar las ingentes cantidades de datos que se están produciendo? ¿qué instituciones podrán hacer analíticas de los usos de todos esos datos relacionados con las publicaciones? Difícilmente podrán ser las bibliotecas porque esas capacidades, especialmente en ciencia, desbordan todas las infraestructuras de bibliotecas existentes.

Estas compañías empiezan a orientar su negocio hacia la oferta de servicios de inteligencia no sobre las publicaciones sino sobre todos esos datos que giran alrededor de la investigación. Desde quién puede ser un investigador promesa al rendimiento comparado de los investigadores de una institución frente a otras en ciertos campos. Como ya ha ocurrido en otros sectores muy digitalizados, comienzan a importar más los metadatos que los datos. Para una compañía de telecomunicaciones o para un servicio de espionaje, hoy tiene más valor los metadatos sobre un número de teléfono (con quién hablamos, cuánto tiempo, por dónde y en qué momento nos movemos) que las propias conversaciones, la información que transmitimos por ese teléfono.

Estos movimientos de empresas editoriales intentando acaparar todo este negocio de datos quizás se pueda convertir en una oportunidad para que las bibliotecas de investigación puedan ejercer como los guardianes del patrimonio de la producción investigadora de los científicos de su institución. De alguna forma se cumplirá una aspiración de los profesionales de la información, las publicaciones en acceso abierto como medio para preservar el patrimonio. Una función que los más acérrimos defensores del acceso abierto veían como secundario puesto que lo que se perseguía no era tanto la preservación de la memoria institucional sino la garantía del acceso abierto para todos.

Nos guste o no, me temo que a los profesionales de las bibliotecas de investigación les tocará lidiar de nuevo con la redefinición de sus funciones respecto a la ciencia abierta, el papel de sus instituciones y la negociación de nuevos servicios con las grandes empresas editoriales. Una historia sin fin.

\section{BIBLIOGRAFÍA}

- ASPESI, C.; BRAND, A. (2020) In pursuit of open science, open access is not enough. Science [en línea], vol. 368, n. $^{\circ}$ 6491, 2020, pp. 574-577 <https://doi.org/10.1126/science. aba3763> [Consulta: 11/05/2020]

- BORREGO, A. (2017) Institutional repositories versus ResearchGate: The depositing habits of Spanish researchers. Learned Publishing, vol. 30, n. ${ }^{\circ}$ 3, 2017, pp. 185-192 <https:// doi.org/10.1002/leap.1099> [Consulta: 11/05/2020]

- MELERO, R.; BABINI, D. (Trads.) (2012) Diez años desde la Budapest Open Access Initiative: Hacia lo abierto por defecto. En Budapest Open Access Initiative (BOAI) [en línea], 2012 <http://www.budapestopenaccessinitiative.org/boai-10translations/spanish> [Consulta: 11/05/2020] 